\title{
ON THE CONCENTRATION OF A FUNCTION AND ITS LAGUERRE-BESSEL TRANSFORM
}

\author{
SElma NegZaOUi AND SAmi ReBHI
}

Abstract. This paper deals with uncertainty principle related to Laguerre-Bessel transform invoking smallness of the support. In particular, we obtain a Benedichs-Amrein-Berthier type theorem related to Laguerre-Bessel transform. As a consequence, we get a global uncertainty inequality and a Heisenberg uncertainty inequality for Laguerre-Bessel transform. Furthermore, invoking essential support, we prove analogous of Donoho-Stark theorem in $L^{1}(\mathbb{K})$ and $L^{2}(\mathbb{K})$, where $\mathbb{K}=[0,+\infty) \times[0,+\infty)$.

Mathematics subject classification (2010): 42B10, 43A62.

Keywords and phrases: Uncertainty principle, partial differential Laguerre-Bessel operator, Donoho-Stark theorem, strongly annihilating pair, Heisenberg inequality.

\section{REFERENCES}

[1] WO. AMREIn AND AM. BerThier, On support properties of $L^{p}$-functions and their Fourier transforms, J. Funct. Anal. 24 (1977), 258-267.

[2] M. BENEDICKS, On Fourier transforms of functions supported on sets of finite Lebesgue measure, J. Math. Anal. Appl. 106 (1985), 180-183.

[3] N. Ben Salem And S. GhobBer, On support properties of functions and their Jacobi transform, Indian J. Pure Appl. Math. 46 (6) (2015), 879-892.

[4] P. Boggiatto, E. CARyPIS AND A. Oliaro, Two aspects of the Donoho-Stark uncertainty principle, J. Math. Anal. Appl. 434 (2016), 1489-1503.

[5] D.L. DONOHO AND P.B. STARK, Uncertainty principles and signal recovery, SIAM J. Appl. Math. 49 (3) (1989) 906-931.

[6] J. Faraut and K. Harzallah, Deux cours d'Analyse Harmonique, in: Ecole d'été d'Analyse Harmonique de Tunis, Birkhaüser, Boston, 1984.

[7] S. Ghobber And P. Jaming, Uncertainty principles for integral operators, Stud. Math. 220 (2014) No. 3, 197-220.

[8] S. Ghobber, Variations on uncertainty principles for integral operators, Appl. 93. 220 (2014), $1057-1072$.

[9] S. GHobBer And P. JAming, Strong annihilating pairs for the Fourier-Bessel transform, J. Math. Anal. Appl. 377 (2011), 501-515.

[10] S. HAMAM AND L. Kamoun, Uncertainty principle inequalities related to Laguerre-Bessel Transform, Math. Inequal. Appl. 16 (2) (2013), 375-387.

[11] W. HEISENBERG, Über den anschaulichen inhalt der quantentheoretischen kinematik und machanik, Z. f. Physik. 43 (1927), 172-198.

[12] E. Jebbari, M. Sifi And F. Soltani, Laguerre-Bessel wavelet transform, Glob. J. Pure Appl. Math. 1 (2005), 13-26.

[13] R.I. Jewett, Spaces with an abstract convolution of measures, Adv. Math., 18 (1975), 1-101.

[14] E. Matusiak, M. Zaydin And T. PRZebinda, The Donoho-Stark uncertainty principle for a finite abelian group, Acta Math. Univ. Comen. New Ser. 73 (2) (2004), 155-160.

[15] F. Soltani, Donoho-Stark uncertainty principle associated with a singular second-order differential operator, Int. J. Anal. Appl. 4 (2014), 1-10. 
[16] H. WeYL, Gruppentheorie und Quantenmechanik, S Hirzel, Leipzig. 1928. Revised English edition: The Theory of Groups and Quantum Mechanics. Methuen London: 1931, reprinted by Dover, New York, 1950. 